This item was submitted to Loughborough's Research Repository by the author.

Items in Figshare are protected by copyright, with all rights reserved, unless otherwise indicated.

\title{
Impromptu crowd science and the mystery of the Bechdel-Wallace test
}

\section{movement}

PLEASE CITE THE PUBLISHED VERSION

http://dx.doi.org/10.1145/2851581.2892580

PUBLISHER

(C) Association for Computing Machinery (ACM)

VERSION

AM (Accepted Manuscript)

LICENCE

CC BY-NC-ND 4.0

REPOSITORY RECORD

Rughinis, Cosima, Reiner Rughinis, and Bogdana Huma. 2019. "Impromptu Crowd Science and the Mystery of the Bechdel-wallace Test Movement". figshare. https://hdl.handle.net/2134/24735. 


\section{Impromptu Crowd Science and the Mystery of the Bechdel-Wallace Test Movement}

Cosima Rughinis

University of Bucharest

Schitu Măgureanu 9

Bucharest, Romania

cosima.rughinis@sas.unibuc.ro

Răzvan Rughiniș

University Politehnica of Bucharest

Splaiul Independenței 313

Bucharest, Romania

razvan.rughinis@cs.pub.ro

\section{Bogdana Humă}

Loughborough University

Epinal Way, Loughborough

LE11 3TU, UK

B.Huma@lboro.ac.uk

Permission to make digital or hard copies of all or part of this work for personal or classroom use is granted without fee provided that copies are not made or distributed for profit or commercial advantage and that copies bear this notice and the full citation on the first page. Copyrights for components of this work owned by others than ACM must be honored. Abstracting with credit is permitted. To copy must be honored. Abstracting with credit is permitted. To copy otherwise, or republish, to post on servers or to redistribute to lists, requires prior specific permission and/or a fee. Request permissions from Permissions@acm.org.

\begin{abstract}
We propose the concept of 'impromptu crowd science' to analyze the Bechdel-Wallace movement. We argue that the practice of using this test to evaluate movies generates a form of digitally distributed knowledge that reveals a challenging conceptual impasse. The current organization of the movement, mainly through blog and newspaper articles, quantitative analyses and wiki syntheses, does not encourage the formulation of theoretically innovative answers, remaining captive in a rhetorical style of balancing pros-and-cons. We propose that hybridizations between such impromptu crowd science and academic inquiries could stimulate crowd theorizing, and we extend this challenge as an invitation for $\mathrm{HCI}$ researchers.
\end{abstract}

\section{Author Keywords}

Crowd science; citizen science; digitally distributed

knowledge; gender representations; the Bechdel-

Wallace test.

\section{ACM Classification Keywords}

H.5.m. Information interfaces and presentation (e.g., HCI): Miscellaneous; K.3.0. Computers and education: general. 


\section{Introduction}

In this paper we explore the movement centered on the Bechdel-Wallace test through the conceptual lens of crowd science. The paper is structured as follows: 1) We first describe the Bechdel-Wallace test movement, discussing its scale and significance. We present its digital genres and we discuss its typical forms of knowledge production. 2) We argue that the BechdelWallace movement is an impromptu form of crowd science, and we distinguish it from typical crowd science projects. 3) We go on to compare the BechdelWallace movement with a similar current stirred by the "Manic Pixie Dream Girl" (MPDG) trope [31]. Through this comparison we highlight specific dynamics of the Bechdel-Wallace movement and we argue that it confronts a theorizing impasse. 4) We propose that this impasse is largely due to the properties of the digital genres through which the Bechdel-Wallace movement operates. 5) As researchers by profession, we could not help but look for merits of joining the efforts of academic practitioners with the Bechdel-Wallace movement. Of course, we found some. 6) We then conclude the paper and we argue that finding a way to bridge the Bechdel-Wallace movement with academic communities in social science and humanities could be an inspiring challenge both for HCI researchers and other fields, such as science communication, gender studies or media critique.

It seems to be an unwritten norm for blogs and articles dealing with the Bechdel-Wallace test to briefly describe it in the introduction - despite living in the age of Internet and, well, Wikipedia [52]. This test may well be the most often described indicator of all times, yet without complete clarity on what it indicates. We take this to be our driving mystery: the practice of applying the Bechdel-Wallace test is thriving in the digital media despite - or even powered by - substantial controversy and some uncertainty on what the test signifies. How could we go about finding out what it indicates?

We will conform to the norm. The Bechdel-Wallace test, often referred to as the Bechdel test, originates in the 1985 comic strip "The Rule" [4], by cartoonist Alison Bechdel, author of "Fun Home" [5] and "Are You My Mother?" [6]. When asked to see a movie, a character in the comic strip announces that she has a rule: she only watches movies that satisfy "three basic requirements". These have become the elements of the test: 1 ) the movie must include at least two women; 2) who should talk to each other; 3 ) and their conversation should be about something else than a man. If a movie fulfills all three requirements, it's a pass; otherwise, it's a fail.

While many writers refer to it as the Bechdel test, Alison Bechdel herself prefers to have it called the Bechdel-Wallace test, since she got the idea for this strip in a discussion with her friend Liz Wallace [26]. In turn, Wallace was most likely inspired by a fragment of Virgina Woolf's essay "A Room of One's Own" from 1929

'Chloe liked Olivia,' I read. And then it struck me how immense a change was there. Chloe liked Olivia perhaps for the first time in literature. (...) All these relationships between women, I thought, rapidly recalling the splendid gallery of fictitious women, are too simple. (...) I tried to remember any case in the course of my reading where two women are represented as friends. (...) They are now and then mothers and daughters. But almost without exception 
they are shown in their relation to men. It was strange to think that all the great women of fiction were, until Jane Austen's day, not only seen by the other sex, but seen only in relation to the other sex. And how small a part of a woman's life is that" [55].

Especially since the 2000s the test has gained increasing popularity, stirring vivid discussions and becoming a topic of countless articles and comments in journals, blogs, vlogs, wikis and other digital genres. Some people have felt inspired or outraged enough to propose derivative or contrary tests. Other participants have sought to apply the test to software, video games, comic books and other media. All in all, the test has become a topic of lively digital interaction and creativity. We refer to this growing interchange as the "Bechdel-Wallace movement".

\section{The Bechdel-Wallace Movement}

The Bechdel-Wallace test appears to be, for many people, a fun and often surprising way of looking at movies. Nowadays we can expect that a major film release will immediately generate discussions on whether the film passes the test or not, and whether this matters at all. For example, Star Wars VII was largely considered to pass the test; this success was widely publicized just after the premiere [51] [19], and many times afterwards - for example here [11] [8] [27]. A Google Search for "Star Wars", "Force Awakens" and "Bechdel test", simultaneously, leads to approx. 39k results, as of 12 Jan. 2016. A Google Search for "Bechdel Test" results in approximatively $362 k$ hits (see Figure 1 ).

Quite a few authors have proposed alternative tests inspired by Bechdel-Wallace, usually aiming to address its shortcomings. We can count the Mako Mori test [39], the Willis test [10], the MacGyver test [17], the reverse Bechdel test [20], the sexy lamp test [56], the Finkbeiner test [3], the Tauriel test [28], the RaleighBecket test [29] and the Masculinity-Movies.com test [45]. In Figure 1 we chart the approximate number of Google Search results for each of these tests, besides another related topic, for the sake of comparison: the "Manic Pixie Dream Girl" [31].

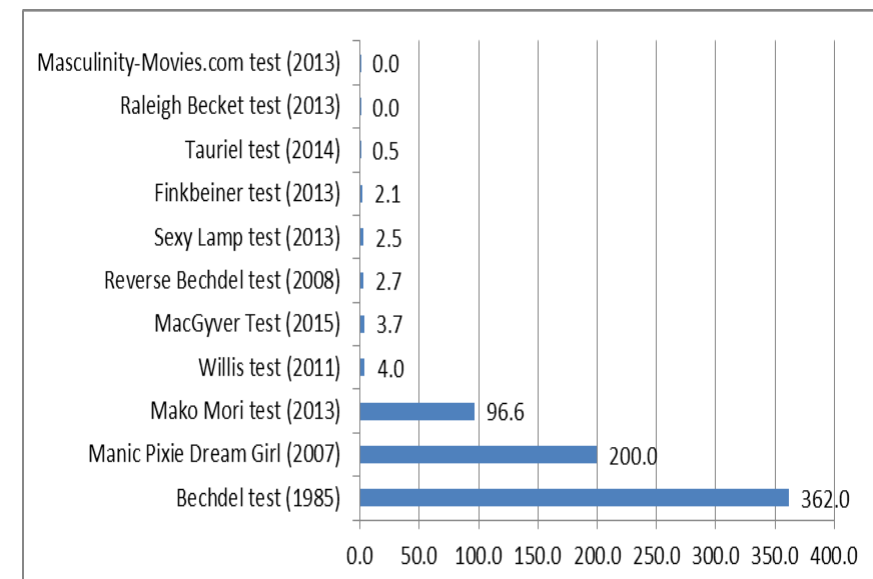

Figure 1. Popularity of various "media tests" (Thou. hits. Authors' data: The chart presents results of our Google Search on exact expressions, such as "Bechdel Test" or "Mako Mori Test", on 12 January 2016).

The Bechdel-Wallace movement relies on several main genres:

- A wealth of blog, vlog and journal articles discussing whether various films pass the test and whether the test is of any value; 
- Digital collaborative media that synthesize information: we find a dedicated Wikipedia page [52], a discussion page on the TVTropes wiki [48], and some discussions on Quora and Stack Exchange.

- The Bechdel Test Movie List collaborative archival platform [13]. Anybody can submit a movie and propose a rating; other people can then contribute to the debate, and the admin will reach a decision of pass or fail for each of the three conditions; the decision can be contested by participants. All in all, the platform now archives 6293 movies in its database (at January 13, 2016); for each movie, readers can see the verdict and the discussion page - which quite often includes diverging opinions. The collaborative archival platform makes possible quantitative analyses on populations of films. Some statistics and charts with verdicts per year are published on bechdeltest.org [14]. Other people have also taken up the task of assembling independent datasets of movies and producing their own pass/fail data, aggregating them into charts or more elaborated studies [25] [43]. Overall, there is a roughly stable tendency for the proportion of films that pass the test, at about $50-60 \%$ per year since the mid ' 90 s.

Therefore we can see that the Bechdel-Wallace movement has created several types of knowledge via digital media and collaborative platforms:

- A significant amount of empirical data concerning pass / fail diagnoses for individual movies, and rates for populations of movies, largely covering the 21th and the 20th centuries;

- Several quantitative analyses based on such data;
- A rich debate on the meaning of the test in relation to the issue of gender representation in movies starting from which people generated a plethora of other tests;

- Two wiki-based syntheses of these discussions (at least), on Wikipedia[52] and TVTropes [49], respectively.

We conclude, at this point, that the Bechdel Wallace movement has created a significant amount of knowledge concerning gender representation in films. What kind of knowledge is it? We found it useful to discuss this movement in relation to the concept of crowd science.

\section{Crowd science}

Crowd science, or citizen science $[16,21,24,35]$, refers to novel forms of organizing scientific inquiries by involving large numbers of people, who are usually not experts, through various digital technologies.

Participants are not required to donate money or computing power, but to donate their thoughts and time by taking over various forms of data collection or problem-solving. Franzoni and Sauermann [21] discuss several such projects and attempt to identify the specific features of crowd science in relation with other knowledge production regimes. They distinguish crowd science from innovation contests and crowd sourcing projects, from traditional science with disclosure of data and logs, and from traditional "Mertonian" science that preserves a closed environment. Crowd science, they argue, is different because of two features: 1 ) it invites a large number of participants who, as a rule, do not know one another, and 2) it openly discloses various intermediate inputs of the scientific process, such as data, methods, as well as less formal tips \& tricks for solving the problems at hand. 
In this respect, the Bechdel-Wallace movement is very similar with citizen science projects: the empirical data on bechdeltest.com, the methods for evaluating films and all sorts of debates and interim results are openly available.

Franzoni and Sauermann also classify crowd science on a bidimensional chart, where the $x$ axis refers to how easy it is to break the problem into independent subtasks, and the $y$ axis refers to the degree of specific expertise required from contributors (ibid.). Thus, they differentiate four types of projects:

1. Distributed coding: it has well-structured subtasks, common human skills are required;

2. Distributed data collection: it has well-structured subtasks, but expert skills are required;

3. Distributed sub-problems: it has less structured subtasks, and some level of expert skills are required (in the middle of the chart area);

4. Collective problem-solving: possible independent sub-tasks are ill-structured and high expert skills are required.

At first sight, the Bechdel Wallace movement seems to be closest to type 1 - a distributed coding project, at least as regards activities on the bechdeltest.com platform. Thousands of contributors solve very well structured substasks, namely deciding and

documenting whether a specific film passes or fails the test conditions. These inputs become then the basis for admin's verdict and further processing.

Moreover, we argue that the Bechdel Wallace movement is also an attempt to clarify the concept of the test itself - which is hotly debated. We find here a distributed, dialogical work of theorizing gender representation and inequalities, in relation with the Bechdel-Wallace test and with the other possible tests advanced by contributors. While most of this effort is dispersed across numerous individual opinions, contributors to the wiki synthesis pages have attempted to put together these ideas. This lay theorizing is similar to type 4 - collective-problem solving - since clarifying concepts is difficult to atomize into subtasks.

We can immediately identify several differences between the Bechdel-Wallace movement and crowd science projects.

1. Unlike most crowd science projects who address issues in the natural sciences and mathematics, the Bechdel-Wallace movement tackles a problem of the social sciences: gender representation. This may have consequences regarding kinds and degrees of participants' skills - but we shall not address them here.

2. There is a notable absence of academic professionals from this public debate. This entire adventure was not initiated by scientists - on the contrary: it has grown mostly independent from and parallel to academic research. Even recent reports on gender representation written by professional researchers in the University environment do not use the Bechdel-Wallace test as an indicator [46] [32]. A Google Scholar search on the Bechdel test reveals surprisingly little. At least we could not find related publications, except for: two articles proposing solutions for automating the test [22] [1], a master's thesis [34] and a 
paper discussing the Bechdel test in relation with Actor-Network Theory [42].

3. Since there is no overarching scientific project to frame participants' activities, theorizing is also left for participants to do. They are in charge with interpreting their own work and giving it direction. While in a typical crowd science project participants know that they are doing crowd science, people involved with the Bechdel-Wallace test are most likely unaware of this (except for us - the paper authors, of course ${ }^{1}$ ).

\section{A comparison: "Manic Pixie Dream Girl"}

In order to better understand the unique features of the Bechdel-Wallace phenomenon, let us examine a similar movement: the "Manic Pixie Dream Girl". This stock character was introduced by Nathan Rabin in 2007 in his critique of Elizabethtown, with the following description: "The Manic Pixie Dream Girl exists solely in the fevered imaginations of sensitive writer-directors to teach broodingly soulful young men to embrace life and its infinite mysteries and adventures" [37]. As Rabin recalls [38], the MPDG has not grown very much immediately after launch - but it caught fire on the Internet after a creation of a list of characters that illustrate the trope [9]. We can see in Figure 1 that its popularity is close in scale to the Bechdel-Wallace test. Rabin actually identifies the Internet as co-author of the MPDG phenomenon: "it's a particular feature of the fast-paced, ephemeral world of online criticism that writers are always seeking quick reference points to contextualize their analysis - so the rise of the MPDG was in large part a creation of the Internet as well"[38]. This may also be true for the BechdelWallace test.

\footnotetext{
${ }^{1}$ We are grateful to Mădălina Manea for this insight.
}

\section{Similarities}

Murray Davis wrote in 1971, in his essay "That's Interesting: Towards a Phenomenology of Sociology and a Sociology of Phenomenology" [18]: "How do theories which are generally considered interesting differ from theories which are generally considered non-interesting? ANSWER: Interesting theories are those which deny certain assumptions of their audience, while non-interesting theories are those which affirm certain assumptions of their audience" ( $p$. 309). We can speculatively find a similar drive in the Bechdel-Wallace and the MPDG movements. Both constructs systematically generate interesting findings. Because of its minimalism, the Bechdel-Wallace test creates the possibility of being legitimately amazed and outraged when a given film does not pass - and even more so when examining the passing rate among populations of films. The MPDG trope has been interesting because it interprets an apparently powerfu feminine character as an instrument in the service of the male character; whenever this clings true, it probably appears as a surprising insight.

Both topics are also swift in application. Anybody who has seen and remembers a movie can verify almost effortlessly the Bechdel-Wallace test. Yet because we do not always remember correctly all conversations between feminine characters, a shade of curiosity remains. Also, there can be a considerable degree of ambiguity in deciding whether or not a conversation between women refers to a man or not: where does a conversation start, and where does it end? How do we decide what is it about? For example, while most viewers considered that Star wars VII passed the test, some argued that the conversation between Maz and Rey on which the verdict depends actually refers to 
Luke (whose name is clearly spoken). Others write against this interpretation [30] [15]. This ambiguity leads to very interesting discussions and turnovers, which maintain interest in the topic. A similar cocktail of quickness, curiosity and ambiguity obtains for the MPDG diagnoses of a certain film.

Once a verdict has been given for a given film, it may be treated as objective, and all ambiguities can be put aside if it is included in statistical analyses and charts. The dialogical work of distributed theorizing does not interfere with the work of distributed statistical analysis.

\section{Differences}

There are some interesting differences between the two movements

- The Bechdel-Wallace test has preserved, in its common application, the spirit of its first appearance, or at least we may infer so, since Bechdel herself has chosen a temperate affiliation with the movement

[7]. On the contrary, Rabin has disowned the MPDG trope, considering that through widespread circulation people have started to apply it wrongly and even against its spirit, degrading valuable feminine characters [38].

- The MPDG trope can be applied only to selected few films, much less than the Bechdel Wallace test which can be used for any film. Thus, the MPDG debate did not result in any quantitative studies -probably for lack of the requisite number of cases.

- While individual authors continue to make lists of characters that fit, in their opinion, the MPDG trope
[31] [33], there is no dedicated archival site for this purpose similar with the bechdeltest.com;

- Still, similar with the Bechdel-Wallace test, the MPDG has its own wiki syntheses: a Wikipedia page [53] and it is also part of the TVTropes site [50], both of them centralizing numerous examples.

While the MPDG did not lead to a large-scale work of data collection and analysis, we can argue that it did lead to a distributed work of theorizing gender representations - particularly gender tropes in media. Although Rabin has disowned his creation, this debate is part of an effort of conceptual clarification that enhances the insight value of this trope.

\section{The theoretical impasse of the Bechdel- Wallace movement}

We observe a longstanding debate in the BechdelWallace movement: contributors attempt to clarify what this test is about. What does the Bechdel-Wallace test indicate - if anything? Many participants consider that the test is at least to some extent relevant and valuable [2] [54]. Saarkesian's vlogs have also contributed to its acclaim $[40,41]$. Others consider it at best irrelevant, and at worst misleading [12].

Arguments against the test's meaningfulness revolve mainly around instances of films featuring strong individual women characters that fail the test (such as Gravity or Pacific Rim). There are also films where trivial exchanges between inconsequential characters lead to a pass verdict. Critics interpret these as false negatives and false positives, respectively. They either ask for abandoning the Bechdel-Wallace test altogether, or propose character-centered tests such as the Mako Mori, the Tauriel and also the Raleigh Becket tests. 
The missing piece in the puzzle is the answer to the question: what can we find out by examining films in relation with the Bechdel-Wallace test? Typical answers that defend the value of the test can be classified in three types, according to their degree of assertiveness:

1. There is not much that we can find out, but it is the least we can do. The test is not that useful to examine individual movies, rather it serves to examine populations. It is a rough proxy or shorthand for gender equality, that starts a needed conversation:

- "The Bechdel test isn't measuring whether a film is a model of gender equality. It doesn't certify that a movie is "good" when it comes to integrating women. And passing it doesn't mean that female characters are well written, play crucial roles in the plot or display meaningful depth of character. But it's the best test on gender equity in film we have and, perhaps more important for our purposes, the only test we have data on" [25];

- It is a "common shorthand to capture whether a film is woman-friendly" [39];

- It is a minimal indicator, best used on populations of films rather than on individual films - see discussions on Quora, for example [36];

- The test "is just a starting point" - to raise filmmakers' awareness [47].

2. The test is a simple indicator for the presence or visibility of women in a given movie or population of films:

- "It just asks the simple question - are women visible?" [44];
- "The test simply indicates whether there is adequate female presence within the film" [54];

- "The test was designed to assess the presence of women in movies" [1].

3. The test is an indicator of the quality of the representations of womanhood through movie characters - for example through active characters, central characters, or deep portraits:

- "The test is used as an indicator for the active presence of women in films and other fiction, and to call attention to gender inequality in fiction due to sexism" [52];

- "But the underlying message the Bechdel Test continues to expose is simply that we do not have enough works of fiction focusing on women" [20];

- The test "articulates something often missing in popular culture: not the number of women we see on screen, but the depth of their stories, and the range of their concerns" (Neda Ulaby cited in [52]).

We consider that none of these answers pinpoint the missing piece - because they do not address the central tension of the Bechdel-Wallace test: if anything, it denies the value of a single, strong feminine character. At the very least, it is a test against Token Girls - even if they end up as meaningful characters. The Bechdel-Wallace test asks for at least two women engaged in conversation about their own concerns. Whatever this test is about, it can be neither the presence of femininity - since the number of women characters would suffice, nor the depth of a character since one deep female character is obviously not good 
enough for this test. Bechdel-Wallace is an instrument to make us perceive something else, something that does not happen in films with powerful but isolated female characters.

Hickey [25] observes a related contrast when he examines the budgets of films according to how many test conditions they pass. Isolated women characters work in a different financial direction than conversation between women; they are, on average, indicators of different narrative patterns: "Looking at the above chart, it's remarkable to see that films that had at least two women in them got higher budgets than films that didn't, but only when those women never spoke to one another. Think about the kind of movie where there are multiple women but they don't talk to each other.

These women are often playing the wives of leading men, damsels in distress or side characters used to help explain the action" (ibid.).

If we accept that there is something significant that the Bechdel-Wallace test indicates, and that the test points in a completely different direction than all evaluations of single characters, we must then find this unknown. The theoretical impasse of the movement consists in its inability to go beyond its often reiterated repertoire of pros-and-cons to find a new answer. What is it about two women in conversation that cannot be obtained with a strong individual character?

The persistence of the Bechdel-Wallace test and its orthogonality on character-centered indicators suggests that it may be about a second dimension of gender representation, different from depth and authenticity of individual stories. We can temporarily propose that it is about autonomy from masculinity - a kind of self- directedness that can only obtain when two women talk with one another with no symbolic strings to a masculine infrastructure of support or validation. The two talking women create a situation similar to what Goffman calls "punctuated segregation"[23]: a brief lapse of a crystal-clear display of femininity. A movie that passes the Bechdel-Wallace test has a chance of communicating that such femininity with no strings attached is valuable, worth watching. Strong individual female characters communicate, on the contrary, that femininity is valuable only if and when it is enhanced by a masculine presence.

Yet, interactions between women in films are extremely scarce, as documented by Mičić in her MA thesis [34]. By analyzing the top grossing 20 movies of all times, she concludes that, of the total time allocated to same sex interaction, female-to-female interaction represents only a minute $4 \%$, with male-to-male interactions accounting for the remaining $96 \%$ (p. 32). If same-sex interaction is valuable to create representations of autonomous femininity, then the Bechdel-Wallace test taps into this extremely scarce resource.

We find a similar position in Selisker's argument. In his one-of-a-kind academic study of the test, Selisker works through the lens of Actor Network Theory, attempting to shift the focus from individuals to relationships, from nodes to edges: "Rather than replacing persons with networks, I see the Bechdel Test as encouraging us to place persons within networks, to see how the structures and forms of the social world both enable and constrain subjects' developments and actions. (...) The Bechdel Test focuses on the presence of relationships that solidify two characters as 
mediators and not intermediaries, nodes and not edges, in a character network." [42]

To conclude, feminine and masculine as gender categories are not defined only through individual attributes of category incumbents, but also through the (power) relationships between the members of these categories. We argue that the Bechdel-Wallace test could be seen as a valuable tool for rendering this relational dimension of gender categories visible.

\section{Properties of digital genres in the Bechdel-}

\section{Wallace movement}

The Bechdel-Wallace movement relies mainly on individual opinion articles in blogs and newspapers, empirical quantitative analyses and wiki syntheses.

These formats do not encourage efforts for overcoming conceptual difficulties. Participants pursue novelty by analyzing the constant incoming flow of films, rather than by trying to delve deeper into the conceptual stakes of the test. Unlike academic researchers, whose professional prestige is enhanced by conceptual innovations and theoretical advances, most authors in the Bechdel-Wallace movement have little to gain from such pursuits. We conjecture that this is why the typical article employing the test does not attempt to overcome these divisions: rather, authors usually invoke a combination of pros-and-cons from the list above, thus legitimizing their position, and then go on with the task at hand of analyzing the movies. The same rhetoric style of listing pros-and-cons, balancing limitations and advantages, is used on wiki syntheses.

Therefore, we conclude that current digital genres supporting the Bechdel-Wallace movement risk remaining captive in a rhetoric of enumerating pros- and-cons. We propose that hybridizations between such impromptu crowd science and academic studies, which have a stake in theoretical syntheses and insights, could stimulate crowd theorizing within the movement. How to achieve such interactions becomes a challenge both for HCI researchers and for practitioners in related fields of the social sciences, such as media critique, gender studies or science communication.

\section{References}

1. Agarwal, A., Zheng, J., Kamath, S.V., Balasubramanian, S., and Dey, S.A.Key Female Characters in Film Have More to Talk About Besides Men: Automating the Bechdel Test. Human

Language Technologies: The 2015 Annual

Conference of the North American Chapter of the $A C L,(2015), 830-840$.

2. Anders, C.J.Why The Bechdel Test Is More Important Than You Realize. io9, 2014 http://io9.gizmodo.com/why-the-bechdel-test-ismore-important-than-you-realize-1586135613.

3. Aschwanden, C.The Finkbeiner Test.

DoubleXScience, 2013.

http://www.doublexscience.org/the-finkbeinertest/.

4. Bechdel, A.The Rule. Dykes to Watch Out For, 2005. http://dykestowatchoutfor.com/wpcontent/uploads/2014/05/The-Rule-cleanedup.jpg.

5. Bechdel, A.Fun Home. Mariner Books, 2007.

6. Bechdel, A.Are You My Mother? Houghton Mifflin, 2012. 
7. Bechdel, A.Testy. 2013.

http://dykestowatchoutfor.com/testy.

8. Berlatsky, N.Star Wars passes the Bechdel test but would the rule's cartoon mascot watch? The Guardian, 2015.

http://www.theguardian.com/film/2015/dec/22/sta $r$-wars-the-force-awakens-feminism-bechdel-testlesbian-culture.

9. Bowman, D., Gillette, A., Hyden, S., Murray, N., Pierce, L., and Rabin, N.Wild things: 16 films

featuring Manic Pixie Dream Girls. A.V.Club, 2008. http://www.avclub.com/article/wild-things-16films-featuring-manic-pixie-dream-g-2407.

10. Carmon, I.The Willis Test Is The New Bechdel Test. Jezebel, 2011. http://jezebel.com/5797747/thewillis-test-is-the-new-bechdel-test.

11. Child, B.Is Star Wars: The Force Awakens really female-friendly? The Guardian, 2015.

http://www.theguardian.com/film/2015/dec/16/sta r-wars-the-force-awakens-jj-abrams-bechdel-testfemale-friendly.

12. Collin, R.Bechdel test is damaging to the way we think about film. The Telegraph, 2013.

http://www.telegraph.co.uk/culture/film/10450463 /Bechdel-test-is-damaging-to-the-way-we-thinkabout-film.html.

13. Contributors of bechdeltest.com.Bechdel Test Movie List. 2015. http://bechdeltest.com/.

14. Contributors of bechdeltest.com.Bechdel Test Movie List - Stats and Graphs. 2015.

http://bechdeltest.com/statistics/.

15. Contributors of bechdeltest.com.Bechdel Test Movie List - Star Wars: The Force Awakens. 2015. http://bechdeltest.com/view/6610/star_wars:_the force_awakens/.

16. Cook, G. How Crowdsourcing is Changing Science. The Boston Globe, 2011.

http://www.humanfaceofbigdata.com/teacherresources/essays/Cook.pdf.

17. Coulombe, N.Portrayal of men in the media: why there needs to be a reverse Bechdel test. 2015. http://www.avoiceformen.com/art-entertainmentculture/portrayal-of-men-in-the-media-why-thereneeds-to-be-a-reverse-bechdel-test/.

18. Davis, M.S.That's interesting!: Towards a phenomenology of sociology and a sociology of phenomenology. Philosophy of the Social Sciences 1,2 (1971), 309-344.

19. Dokterman, E.Star Wars: The Force Awakens Reportedly Passes the Bechdel Test. Time, 2015. http://time.com/4149014/star-wars-the-forceawakens-bechdel-test/.

20. Fecke, J.The Reverse Bechdel Test. Alas! A Blog, 2008. http://amptoons.com/blog/2008/10/03/thereverse-bechdel-test/.

21. Franzoni, C. and Sauermann, H.Crowd science: The organization of scientific research in open collaborative projects. Research Policy 43,1 (2014), 1-20.

22. Garcia, D., Weber, I., and Garimella, V.R.K.Gender Asymmetries in Reality and Fiction: The Bechdel Test of Social Media. (2014)

23. Goffman, E.Gender Advertisements. Harper \& Row 1979. 
24. Gura, T.Citizen science: Amateur experts. Nature 496, 7444 (2013), 259-261.

25. Hickey, W.The Dollar-And-Cents Case Against Hollywood's Exclusion of Women. FiveThirtyEight 2014. http://fivethirtyeight.com/features/thedollar-and-cents-case-against-hollywoodsexclusion-of-women/.

26. Hooton, C.Please stop calling it the Bechdel Test, says Alison Bechdel. Independent, 2015.

http://www.independent.co.uk/arts-

entertainment/films/news/please-stop-calling-itthe-bechdel-test-says-alison-bechdel10474730.html.

27. Hooton, C.Star Wars: The Force Awakens passes the Bechdel Test with flying colours. Independent, 2015. http://www.independent.co.uk/arts-

entertainment/films/features/star-wars-the-forceawakens-passes-the-bechdel-test-with-flyingcolours-a6777086.html.

28. JennIRL.the Bechdel test, the Ellen Willis test, ALL THE TESTS: or, a handy guide to feminist critiques of narrative. 2015

http://jennirl.tumblr.com/post/73246311962/thebechdel-test-the-ellen-willis-test-all-the.

29. Joanna at Geekalitarian. A New New Bechdel Test. Geekalitarian, 2013.

https://geekalitarian.wordpress.com/2013/08/21/a -new-new-bechdel-test/.

30. Jusino, T.The Force Awakens May or May Not Pass the Bechdel-Wallace Test, But Does It Matter? The Mary Sue, 2015. http://www.themarysue.com/theforce-awakens-bechdel-wallace/.

31. Kornhaber, S.Why 'Manic Pixie Dream Girl' Won't Go Away. The Atlantic, 2015. http://www.theatlantic.com/entertainment/archive /2015/09/the-manic-pixie-dream-girlrepents/404953/.

32. Lauzen, M.M.It's a Man's (Celluloid) World: OnScreen Representations of Female Characters in the Top 100 Films of 2014. Center for the Study of Women in Television and Film, San Diego State University, 2015.

http://womenintvfilm.sdsu.edu/files/2014_Its_a_M ans World Report.pdf.

33. Loftus, J.The Definitive List of Manic Pixie Dream Girls in Film and Television. BDCWire, 2015.

http://www.bdcwire.com/the-definitive-list-ofmanic-pixie-dream-girls-in-film-and-television/.

34. Mičić, Z.Female Interactions on Film: Beyond the Bechdel Test. A quantitative content analysis of same-sex-interactions of top 20 box office films. 2015. http://www.diva-

portal.org/smash/get/diva2:821217/FULLTEXT01.p df.

35. Prpić, J. and Shukla, P.Crowd Science: Measurements, Models, and Methods. (2015).

36. Quora Contributors. What are the flaws in the Bechdel test? Quora, 2014

https://www.quora.com/What-are-the-flaws-inthe-Bechdel-test.

37. Rabin, N.The Bataan Death March of Whimsy Case File \#1: Elizabethtown. A.V.Club, 2007.

http://www.avclub.com/article/the-bataan-deathmarch-of-whimsy-case-file-1-emeli-15577.

38. Rabin, N.I'm sorry for coining the phrase "Manic Pixie Dream Girl." Salon, 2014.

http://www.salon.com/2014/07/15/im_sorry_for_c oining_the_phrase_manic_pixie_dream_girl/. 
39. Romano, A.The Mako Mori Test: 'Pacific Rim' inspires a Bechdel Test alternative.

www. dailydot.com, 2013.

http://www.dailydot.com/fandom/mako-mori-testbechdel-pacific-rim/.

40. Saarkesian, A.The Bechdel Test for Women in Movies. Feminist Frequency, 2009.

https://www.youtube.com/watch?v=bLF6sAAMb4s.

41. Saarkesian, A.The Oscars and The Bechdel Test.

Feminist Frequency, 2012.

https://www.youtube.com/watch?v=PH8JuizIXw8.

42. Selisker, S.The Bechdel Test and the Social Form of Character Networks. New Literary History 46, 3 (2015), 505-523

43. Silk Team.Women in Film: A Data Analysis of 1500 Movies on Bechdel Test Criteria. 2015.

http://women-in-film.silk.co/.

44. Silverstein, M.A Closer Look at the Bechdel Rating. Forbes, 2013

http://www.forbes.com/sites/melissasilverstein/20

13/11/12/a-closer-look-at-the-bechdel-

rating/\#2715e4857a0b4619c3e6ea28.

45. Skjellum, E.F.The Bechdel test: Application historical context, and introducing a male

equivalent. http://www.masculinity-movies.com/, 2013. http://www.masculinity-

movies.com/articles/the-bechdel-test-applicationhistorical-context-and-introducing-a-maleequivalent.

46. Smith, S.L., Choueiti, M., and Pieper, K.Gender Inequality in Popular Films: Examining On Screen Portrayals and Behind-the-Scenes Employment Patterns in Motion Pictures Released between 2007-2013. 2014. http://annenberg.usc.edu/pages/ /media/MDSCI/ Gender Inequality in Film 2007-2013 Final for Publication.ashx.

47. Steel, S., Rex, T., and Culp, M.Pass the Bechdel Test. 2015

http://www.passthebechdeltest.com/faq/.

48. TVTropes Contributors.Useful Notes: The Bechdel Test. tvtropes.org, 2015

http://tvtropes.org/pmwiki/pmwiki.php/UsefulNote s/TheBechdelTest.

49. TVTropes Contributors.Useful Notes: The Bechde Test. tvtropes.org, 2015.

50. TVTropes Contributors. Manic Pixie Dream Girl. tvtropes.org, 2015.

http://tvtropes.org/pmwiki/pmwiki.php/Main/Manic PixieDreamGirl.

51. Vincent, A.The Feminist Force Awakens: Star Wars 7 passes the Bechdel Test. The Telegraph, 2015. http://www.telegraph.co.uk/film/star-wars-theforce-awakens/passes-bechdel-test-leia-rey/.

52. Wikipedia Contributors.Bechdel Test. Wikipedia, The Free Encyclopaedia, 2015.

https://en.wikipedia.org/wiki/Bechdel_test.

53. Wikipedia Contributors. Manic Pixie Dream Girl. Wikipedia, The Free Encyclopedia, 2015. https://en.wikipedia.org/wiki/Manic_Pixie_Dream_

54. Wilson, S.Bechdel Rule still applies to portrayal of women in films. OUDAILY, 2012

http://www.oudaily.com/I_and_a/arts_and_enterta inment/column-bechdel-rule-still-applies-toportrayal-of-women-in/article_d3dc6a7d-8fcb589c-885a-649fe33db5e1.html. 
55. Woolf, V.A Room of One's Own. 1929.

https://ebooks.adelaide.edu.au/w/woolf/virginia/w

91r/index.html.

56. Yehl, J.Kellu Sue DeConnick Talks Captain Marvel,

Pretty Deadly, and the Sexy Lamp Test. IGN, 2013.

http://www.ign.com/articles/2013/06/20/kelly-

sue-deconnick-talks-captain-marvel-pretty-deadly-

and-the-sexy-lamp-test. 